\title{
Risco da rentabilidade em pisciculturas de tambaqui nos estados do Amazonas, Rondônia e Roraima
} Risk of profitability in tambaqui fish farms in the states of Amazonas, Rondônia and Roraima

\section{Dreyfus Lincoln Silveira Feitoza ${ }^{1}$; Daniel Yokoyama Sonoda ${ }^{2}$; Lucirene Aguiar de Souza ${ }^{3}$}

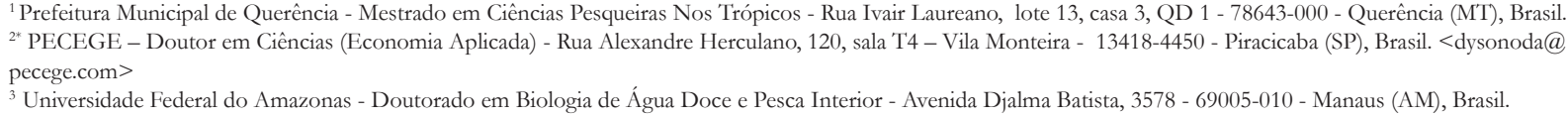

${ }^{1}$ Prefeitura Municipal de Querência - Mestrado em Ciências Pesqueiras Nos Trópicos - Rua Ivair Laureano, lote 13, casa 3, QD 1 - $78643-000$ - Querência (MT), Brasil $2^{2 *}$ PECEGE - Doutor em Ciências (Economia Aplicada) - Rua Alexandre Herculano, 120, sala T4 - Vila Monteira - 13418-4450 - Piracicaba (SP), Brasil. <dysonoda@ pecege.com>

${ }^{3}$ Universidade Federal do Amazonas - Doutorado em Biologia de Água Doce e Pesca Interior - Avenida Djalma Batista, 3578 - 69005-010 - Manaus (AM), Brasil.

\section{Resumo}

A produção da piscicultura brasileira vem crescendo continuamente e a produção de tambaqui na Região Norte contribui com esse crescimento, principalmente nos estados do Amazonas, Rondônia e Roraima. Essas regiões dependem cada vez mais informações técnicas e econômicas sobre a produção do tambaqui para não só aumentar a sua produtividade e rentabilidade, como também mitigar os impactos dos riscos técnicos e econômicos da atividade. O objetivo deste estudo foi calcular e simular os cenários da rentabilidade da produção do tambaqui no sistema de viveiros escavados em propriedades típicas dos estados do Amazonas, Rondônia e Roraima, visando o mercado consumidor da cidade de Manaus, AM. Os sistemas avaliados nos estados em tela possuem viabilidade técnica e econômica, apresentando para a propriedade típica do

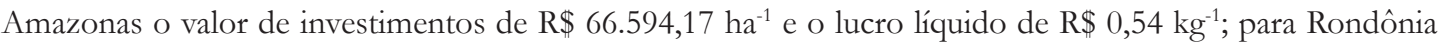
o valor de investimento de $\mathrm{R} \$ 49.080,19 \mathrm{ha}^{-1}$ e lucro líquido de $\mathrm{R} \$ 0,25 \mathrm{~kg}^{-1}$ e para Roraima o valor de investimento de $\mathrm{R} \$ 43.777,18 \mathrm{ha}^{-1}$ e o lucro líquido de $\mathrm{R} \$ 0,94 \mathrm{~kg}^{-1}$. O estado Amazonas apresentou lucro líquido de $76 \%$ e $64 \%$ na análise de cenário de preços e técnico, respectivamente. Rondônia apresentou $92 \%$ e $64 \%$ de chance de lucro líquido nas simulações de preço e técnicas, respectivamente, e Roraima apresentou $100 \%$ das combinações propostas com lucro líquido.

Palavras-chave: análise de cenários, análise de risco, avaliação econômica, piscicultura

\begin{abstract}
Production of farmed fish in Brazil has increased steadly over the last years, the production of tambaqui in North Brazil contributing to this growth, mainly in the states of Amazonas, Rondônia and Roraima. These regions rely on technical and economic information on tambaqui production to increase their productivity and profitability, and to mitigate the impacts of technical and economic risks over time. The objective of this study was estimating and simulatingscenarios of profitability on tambaqui production in typical fish farms of the states of Amazonas, Rondônia and Roraima, targeting the market of Manaus-AM. Technical and economic feasibility of fish farming operations were: at Amazonas the investments were $\mathrm{R} \$ 66,594.17 \mathrm{ha}^{-1}$ and net profit of $\mathrm{R} \$ 0.54 \mathrm{~kg}^{-1}$, for Rondônia the investments were $\mathrm{R} \$ 49,080.19 \mathrm{ha}^{-1}$ and net profit of $\mathrm{R} \$ 0.25 \mathrm{~kg}^{-1}$, and for Roraima investments were $\mathrm{R} \$ 43,777.18 \mathrm{ha}^{-1}$ and the net proft of $\mathrm{R} \$ 0.94 \mathrm{~kg}^{-1}$. Amazonas reported net profit of $76 \%$ and $64 \%$ in prices and technical scenario analysis, respectively. Rondônia presented $92 \%$ and $64 \%$ chance of net profit in price and technical simulations respectively and Roraima presented $100 \%$ of proposed combinations with net profit.
\end{abstract}

Keywords: scenario analysis, risk analysis, economic analysis, fish farming

\section{Introdução}

Apesar da falta de confiabilidade nos dados das estatísticas pesqueiras recentes, a produção e o consumo de pescados vem crescendo no Brasil (Sonoda et al., 2015). Não se pode ignorar que boa parte da oferta do pescado nacional é suprida pela importação (Barone et al., 2017), nem que a região norte tem uma dinâmica própria na oferta e demanda por pescados pois se trata de um grande produtor e consumidor per capita (Sonoda et al., 2012).
O conceito moderno de aquicultura engloba a sustentabilidade, definida como a produção economicamente atrativa e lucrativa de organismos aquáticos em confinamento, tendo na sua conjuntura a integração da economia, sustentabilidade e desenvolvimento social (Valenti, 2008). O levantamento e o uso de informações técnicas e econômicas sobre a piscicultura são ferramentas fundamentais para aumentar a produtividade e rentabilidade, além auxiliar a mitigar os impactos negativos dos riscos técnicos e econômicos da atividade ao longo do tempo (Sonoda et al., 2016). 
A região Norte tem grande vocação para o desenvolvimento dessa piscicultura, pois possui um vasto território, grande riqueza em recursos hídricos e clima favorável à produção de organismos aquáticos (Brasil, 2013). O tambaqui (Colossoma macropomum) está entre as espécies nativas mais produzidas naquela região (SUFRAMA, 2003), com destaque para os estados de Rondônia, como o maior estado produtor, seguido por Roraima e o Amazonas, que aparece como o terceiro estado em piscicultura da região (Brasil, 2015). Segundo dados da Suprintendência da Zona Franca de Manaus [Suframa] (2003), a Região Norte ainda possui um grande potencial para ampliação da piscicultura.

Apesar do grande potencial produtivo da piscicultura da região, ainda existem gargalos que estrangulam o crescimento do setor (Oliveira, 2015) ${ }^{1}$. De acordo com Padua et al. (2008), os piscicultores na sua maioria não possuem conhecimento ou direcionamento técnico para explorar o melhor desta atividade zootécnica e, consequentemente, sem o devido planejamento e o gerenciamento adequado das pisciculturas, não acabam tendo o resultado satisfatório. A avaliação econômica na piscicultura torna-se uma ferramenta indispensável para subsidiar a tomada de decisão de piscicultores/empreendedores em seus investimentos na atividade. Este estudo teve como objetivo determinar a rentabilidade considerando diferentes combinações de cenários de risco em empreendimentos típicos de produção de tambaqui em viveiros escavados nos estados do Amazonas, Rondônia e Roraima, para o mercado consumidor a cidade de Manaus, AM.

\section{Material e Métodos}

O tambaqui é uma espécie nativa dos rios Amazonas, Orinoco e seus afluentes. Possui uma forte arcada dentária, com a finalidade de lhe permitir quebrar os frutos e sementes que caem na água durante o período de cheia dos rios, seu hábito alimentar é bem amplo, constituindo-se de frutos, sementes, insetos, caramujos e raramente de outros peixes (Araújo-Lima e Gouding, 1998). É um peixe muito apropriado para o cultivo, pois apresenta carne saborosa, crescimento rápido, fácil manuseio, grande rusticidade (Val et al., 2000), é a espécie que mais vem tendo um crescimento de cultivo nas várias regiões brasileiras (Affonso et al., 2009; Dairiki e Silva, 2011; Embrapa, 2013). Este peixe é o mais cultivado em módulos de viveiro escavado ou semi-escavado (Marinho et al., 2009).

A pesquisa aplicou questionários em pisciculturas dos municípios que fazem parte do cinturão produtivo da piscicultura nos três estados descritos: 1) Amazonas: nos municípios de Manaus, Presidente Figueiredo,
Rio Preto da Eva, Iranduba, Manacapuru e Itacoatiara (Gandra, 2010; Oliveira et al., 2012); 2) Rondônia: pisciculturas situadas nos Municípios de Porto Velho, Ariquemes, Ji-paraná, Ouro preto, Pimenta Bueno, Rolim de Moura (Neapl, 2007; Xavier, 2013); e 3) Roraima: nos municípios de Caracaraí, Rorainópolis, Bonfim, Caroebe, São Luís, São João da Baliza, Alto Alegre, Iracema, Mucajaí, Amajarí, Cantá (Pereira et al., 2013).

O formulário empregado foi adaptado do questionário de Albuquerque et al. (2008) que apresentava perguntas abertas e de múltipla escolha. Durante a aplicação do questionário foram abordados 30 piscicultores de cada estado de pelo menos duas ou mais propriedades de cada munícipio listado no período de 02 fev. 2016 a 31 jul. 2017. As propriedades pesquisadas foram selecionadas de modo aleatório e a partir de participação voluntária do produtor através de assinaturas nos Termos de Consentimento Livre e Esclarecido [TCLE].

O método utilizado para análise das informações coletadas foi o custo de total de produção, conforme descrito por Matsunaga (1976), estão descritos nas equações 1 e 2 .

$$
\mathrm{COT}=\mathrm{COE}+\text { Remuneração }
$$

onde, COT: é o custo operacional total; o COE é o custo operacional efetivo: soma dos custos com mão de obra contratada, dos respectivos encargos sociais, da aquisição de todos os insumos e da manutenção dos equipamentos e estrutura, ou seja, a despesa efetiva ou desembolso realizado pelo produtor durante o ciclo produtivo; e, o item Remuneração referente-se ao pagamento dos produtores e a depreciação de bens de capital (infraestrutura, máquinas e equipamentos) que foi calculada pelo método linear.

$$
\mathrm{CTP}=\mathrm{COT}+\text { juros }
$$

onde, CTP: é o custo total de produção e os juros, ou custo de oportunidade do capital, são com os custos relativos aos juros anuais do capital referente ao investimento (uso alternativo da terra, juros sobre investimentos em infraestrutura e de capital de giro).

Para o cálculo da rentabilidade foi adotado o método descrito por Martin et al. (1995), conforme eq. 2 a 6.

$$
\mathrm{RB}=\mathrm{PA} \times \mathrm{PV}
$$

onde, RB: é a receita bruta; PA: é a produção anual; PV: é o peço médio de venda.

$$
\mathrm{MB}=\mathrm{RB}-\mathrm{COE}
$$

onde, MB: é a margem bruta

${ }^{1}$ Oliveira, B. 2015. Análise de Cadeia Global de Valor e Risco na Piscicultura no Tocantins. Dissertação de Mestrado (Desenvolvimento Regional) Universidade Federal do Tocantins, Tocantins/TO, p. 106. 


$$
\mathrm{LO}=\mathrm{RB}-\mathrm{COT}
$$

onde, LO: é o lucro operacional.

$$
\text { Lucro }=\mathrm{RB}-\mathrm{CTP}
$$

A análise de risco considerou a resposta do Lucro em função do gradiente dos cenários pessimista, realista e otimista, submetido às variáveis econômicas: preço da ração $\left(R \$ \mathrm{~kg}^{-1}\right)$ e o preço de venda $\left(\mathrm{R} \$ \mathrm{~kg}^{-1}\right)$; e à variáveis técnicas: taxa de conversão alimentar $(\mathrm{kg} \mathrm{kg}$ $\left.{ }^{1}\right)$ e a sobrevivência (\%), mantendo-se todas as demais variáveis constantes. A partir do cenário típico (médio ou realista), a variação dos parâmetros foi feita segundo os valores mínimos e máximos encontrados na amostra para os extremos (otimista e pessimista) e para os valores intermediários foi usado o valor típico acrescidos ou subtraídos de um desvio padrão.

Cabe observar que todas as comparações de preços feitas entre este estudo e os diferentes papers, encontramse em valores nominais.

\section{Resultados e Discussão}

A piscicultura no estado do Amazonas, de acordo com Rolim (1995), teve seu começo na década de oitenta, quando foi lançado o programa governamental de apoio ao desenvolvimento da piscicultura no estado. $\mathrm{O}$ cultivo de peixes em ambientes confinados para alimentação humana é importante para a população Amazonense (Freitas, 2003). Gandra (2010) e Tortolero $(2015)^{2}$ mencionaram a existência de aproximadamente 3.614 piscicultores em atividade e o Instituo Brasileiro de Geografia e Estatística [IBGE] (2015) descreve que estes são cerca de 2.980 piscicultores no estado. Segundo dados extraídos da Sepror (2007), a área alagada para o cultivo de peixes em cativeiro no estado do Amazonas é de aproximadamente 2.000 ha. Ambos, Gandra (2010) e IBGE (2015), informaram que os peixes cultivados nos mais diversos sistemas de produção são o tambaqui, matrinxã, pirarucu e algumas outras espécies.

O IBGE (2015) também relatou que o estado do Amazonas teve um incremento de produção de 49,29\% no ano de 2013 para 2014, em decorrência do pescado oriundo da piscicultura. Por sua vez, Gandra (2010), Oliveira et al. (2012) e Empresa Brasileira de Pesquisa Agropecuária [Embrapa] (2013) relataram que o polo produtor das pisciculturas amazonenses está instalado na região metropolitana de Manaus, totalizando cerca de 1.700 ha de área alagada para produção de peixes em cativeiro.

Segundo dados do Instituto de Proteção Ambiental do Amazonas [Ipaam] (2007), Conselho Estadual do
Meio Ambiente do Amazonas [Cemaam] (2008) e Pantoja et al. (2015), as pisciculturas do estado apresentam módulos produtivos compostos por viveiro escavado ou semi-escavado (Marinho et al., 2009), barragens (Izel e Melo, 2004), canais de igarapés (Fim et al., 2009), tanquerede (Embrapa, 2002).

Oliveira et al. (2012) e Secretaria de Produção Rural do Amazonas [Sepror-AM] (2007) apontaram os gargalos do setor produtivo, em que se destacam assistência técnica, obtenção de insumos com preços competitivos para produção (alevinos, ração, calcário, farelo e ureia) e a comercialização dos produtos. De acordo com trabalhos realizados pela Suframa (2003), Riva et al. (2010); Campos et al. (2015) e Freitas et al. (2015) apontaram que o maior volume de comercialização da piscicultura da região norte é para a cidade de Manaus. Os preços praticados na comercialização variam em função do seu peso final. O comércio do tambaqui é feito in natura nos mercados, feiras, frigoríficos, pesque pague e o próprio consumidor final. O mercado de Manaus possui uma particularidade, em que os tambaquis de cultivo acima de $3 \mathrm{~kg}$ são os preferidos pelos consumidores. Desta forma, os tambaquis oriundos de Rondônia possuem o melhor preço em função do maior peso final e os peixes produzidos no Amazonas apresentam o preço mais baixo em função do seu menor peso.

Dados extraídos do boletim da Suframa (2003) descrevem que a piscicultura em Rondônia, na década de 1980 era uma atividade que se desenvolveu de forma não organizada como fonte de renda para pequenos produtores e poder de comercialização do produto limitado. Este estudo descreve o tambaqui como a espécie alvo favorita, devido a sua rusticidade, produção anual média de $4 \mathrm{t} \mathrm{ha}^{-1}$ e por apresentar um pacote tecnológico bem estabelecido.

No ano de 2003, o poder público, através do Governo do Estado de Rondônia por intermédio da Secretaria de Agricultura e Desenvolvimento Econômico e Social (Seapes), em uma parceria com o Sebrae-RO, Empresa de Assistência Técnica e Extensão Rural de Rondônia [Emater-RO] e as Associações de Produtores do estado de Rondônia, realizaram mobilizações, através de reuniões, seminários e oficinas, com o intuito de divulgar, expandir e discutir ações que pudessem alavancar o desenvolvimento da atividade no estado. Através dessas mobilizações surgiu um plano gestor para atividade e desde então, a piscicultura tem se desenvolvido de forma acelerada.

Para Xavier $(2013)^{3}$, a piscicultura familiar é muito importante, pois representava $83,62 \%$ do quantitativo total dos piscicultores do estado, com os módulos

Tortolero, S.A.R. 2015. Tese de Doutorado - Piscicultura integrada na Amazônia: favorecimento a produção de perifiton e seus efeitos no crescimento do jaraqui de escama grossa em monocultivo e policultivo com tambaqui. 129 p.

${ }^{3}$ Xavier, R.E. 2013. Caracterização e prospecção da cadeia produtiva da piscicultura no Estado de Rondônia. Dissertação (Mestrado em

Desenvolvimento Regional e Meio Ambiente) Fundação Universidade Federal de Rondônia / UNIR. 103p.: il. Porto Velho, Rondônia. 
produtivos variando do entre 1 a 5 hectares $(3 \mathrm{mil} \mathrm{ha}$ no total). Os piscicultores considerados de médio porte representavam 15,38\% e com lâminas de água variando entre 5 até 50 ha (total de 4.070 ha) e por fim, o estado de Rondônia, apresentava 11 piscicultores de grande porte, com a lâmina de água superior a 50 e até 750 ha de área de produção representando 1\% dos piscicultores do estado.

Segundo Núcleo Estadual de Apoio aos Arranjos Produtivos Locais de Rondônia [NEAPL/RO] (2007), as pisciculturas fornecem pescado fresco e apenas uma pequena parcela passava por algum tipo de processamento industrial, grande parte da produção com destino para o Amazonas. Campos et al. (2015) relatou que os peixes produzidos em Rondônia, possui custo de produção menor do que em Roraima, pois tem fácil acesso ao mercado de insumos com preços de compra mais baixos do que os praticados nos estados vizinhos da região norte. Porém, o custo de entrega do pescado para o mercado consumidor do Amazonas faz com que essas diferenças de custos se equilibrem. O tempo de transporte do peixe pode durar de 5 a 15 dias, exigindo que os procedimentos de abate, armazenamento e conservação sejam mais cautelosos para reduzir os efeitos da rápida deterioração do pescado.

Pereira et al. (2013) descreve que a piscicultura de Roraima, desponta como uma das principais atividades econômicas do agronegócio. De forma estratégica, a atividade piscícola passa por uma estruturação consistente da sua indústria de processamento e estrutura de comercialização. Destaca-se no estado de Roraima seu tamanho em termos territoriais, a constituição das suas bacias e microbacias hidrográficas, a sua localização e proximidades com outros países e a proximidade com o estado do Amazonas.
Dados levantados pelo Instituto Brasileiro do Meio Ambiente e dos Recursos Naturais Renováveis [IBAMA], Movimento dos Pequenos Agricultores [MPA] e IBGE relativos à produção no ano de 2013, mostraram que Roraima teve uma produção de 16.134 toneladas de tambaqui (com 90\% do volume total produzido) e em segundo lugar a matrinxã (Brycon amazonicus) com 10\% de participação. Os viveiros variavam entre $1050 \mathrm{~m}^{2}$ a 3.000 $\mathrm{m}^{2}$, as barragens variavam de $2 \mathrm{a} 10$ ha de lâmina de água (Pereira et al., 2013; Campos et al., 2015). De acordo com o diagnóstico da piscicultura do estado de Roraima, executado pelo Serviço Brasileiro de Apoio às Micro e Pequenas Empresas de Roraima [Sebrae-RR] (2008), os preços praticados em Roraima para Manaus variavam de $\mathrm{R} \$ 5,50$ a 6,30 por $\mathrm{kg}$ no atacado, dependendo do peso de abate do tambaqui.

\section{Sistema de produção típico de tambaqui nos estados do Amazonas, Rondônia e Roraima}

A partir das informações levantadas e referências da literatura foram definidos os sistemas de produção típicos para os respectivos estados considerando área alagada (ha), densidade de estocagem (juvenis $\mathrm{m}^{-2}$ ), sobrevivência (\%), taxa de conversão alimentar ( $\mathrm{kg}$ ração $\mathrm{kg}$ peixe $\left.^{-1}\right)$, peso final $(\mathrm{kg})$, preços de ração e de venda dos peixes $\left(R \$ \mathrm{~kg}^{-1}\right)$, valor de investimento $\left(\mathrm{R} \$ \mathrm{ha}^{-1}\right)$ para cada estado. O investimento foi composto por projeto de piscicultura; construção dos viveiros, do depósito de ração, da rede elétrica; aquisição de bomba hidráulica, de balança digital, de kit de análise de água, de rede de arrasto de malha de $25 \mathrm{~mm}$, de puçá (bag), de aeradores, tratores e de outros investimentos.

Os dados técnicos de custo e de preço foram obtidos através de estatísticas descritivas: medidas de tendência central (média), medidas de dispersão dos dados (variância e desvio padrão) (Tabela 1).

Tabela 1. Informações levantadas para o cálculo dos sistemas de produção típicos dos estados do Amazonas, Rondônia e Roraima

\begin{tabular}{|c|c|c|c|c|c|c|c|c|c|c|}
\hline Estado & & Viveiro & Dens. & Sobrev. & C.A. & Peso unit. & P. raç. 32\% & P. raç. $28 \%$ & Invest. & P. Venda \\
\hline & & --- ha --- & $-\mathrm{p} \mathrm{m} \mathrm{m}^{-2}$ & & $-\mathrm{kg} \mathrm{kg}^{-1}-$ & --- kg --- & $-\mathrm{R} \$ \mathrm{~kg}^{-1}-$ & $--\mathrm{R} \$ \mathrm{~kg}^{-1}--$ & - $\mathrm{R} \$ \mathrm{ha}^{-1}$ & - $\mathrm{R} \$ \mathrm{~kg}^{-1}-$ \\
\hline $\mathrm{AM}$ & méd. & 3,37 & 0,62 & 0,64 & 1,81 & 2,67 & 2,16 & 1,77 & 56.898 & 6,24 \\
\hline $\mathrm{AM}$ & d.p. & 4,19 & 0,27 & 0,16 & 0,12 & 0,45 & 0,16 & 0,19 & 59.129 & 0,43 \\
\hline $\mathrm{AM}$ & $\min$. & 0,20 & 0,30 & 0,40 & 1,60 & 1,50 & 2,00 & 1,52 & 45.000 & 5,40 \\
\hline $\mathrm{AM}$ & Máx & 20,00 & 1,00 & 0,88 & 2,10 & 3,50 & 2,58 & 2,12 & 60.000 & 7,00 \\
\hline $\mathrm{RO}$ & méd. & 15,02 & 0,42 & 0,61 & 1,66 & 3,09 & 1,81 & 1,44 & 42.440 & 4,85 \\
\hline $\mathrm{RO}$ & d.p. & 12,40 & 0,12 & 0,10 & 0,11 & 0,24 & 0,05 & 0,05 & 44.275 & 0,10 \\
\hline $\mathrm{RO}$ & min. & 0,50 & 0,30 & 0,43 & 1,50 & 2,50 & 1,71 & 1,35 & 40.000 & 4,70 \\
\hline $\mathrm{RO}$ & Máx & 60,00 & 0,70 & 0,80 & 1,85 & 3,50 & 1,91 & 1,52 & 40.000 & 5,10 \\
\hline $\mathrm{RR}$ & méd. & 77,70 & 0,39 & 0,72 & 1,78 & 2,99 & 2,04 & 1,74 & 40.423 & 5,91 \\
\hline $\mathrm{RR}$ & d.p. & 130,05 & 0,11 & 0,14 & 0,13 & 0,30 & 0,07 & 0,08 & 39.914 & 0,20 \\
\hline $\mathrm{RR}$ & $\min$. & 0,50 & 0,30 & 0,50 & 1,40 & 2,50 & 1,92 & 1,60 & 40.000 & 5,50 \\
\hline $\mathrm{RR}$ & Máx & 600,00 & 0,70 & 0,97 & 1,90 & 3,74 & 2,24 & 1,88 & 40.000 & 6,30 \\
\hline
\end{tabular}


A propriedade típica no Amazonas apresenta lâmina de água média de 3,37 ha de viveiro escavado, para a produção do tambaqui; a densidade de estocagem de 0,62 peixes $\mathrm{m}^{-2}$; peso inicial dos alevinos contendo $15 \mathrm{~g}$; a taxa de conversão alimentar de 1,81 ( $\mathrm{kg}$ de ração kg de peixe $\left.^{-1}\right)$; a taxa de sobrevivência final de $64 \%$; o peso final de abate de 2,67 kg; a produtividade de $10.620 \mathrm{~kg} \mathrm{ha}^{-1} \mathrm{e}$ a duração do ciclo de produção de 12 meses (Tabela 2).

Tabela 2. Propriedade típica de tambaqui do Amazonas

\begin{tabular}{lcr}
\hline Índices zootécnicos & Unidade & \multicolumn{1}{c}{ Qtde } \\
\hline Área alagada & ha & 3,37 \\
Densidade de estocagem & peixes m${ }^{-2}$ & 0,62 \\
Quantidade de peixes estocados & unidade & $20.970,00$ \\
Peso inicial dos peixes & $\mathrm{g}$ & 15,00 \\
Taxa de conversão alimentar & $\mathrm{kg} \mathrm{kg}^{-1}$ & 1,81 \\
Taxa de sobrevivência & $\%$ & 0,64 \\
Peso médio de abate & $\mathrm{kg}$ & 2,67 \\
Produção ano & $\mathrm{kg}$ & $35.747,00$ \\
Produtividade & $\mathrm{kg} \mathrm{ha}^{-1}$ & $10.620,00$ \\
Tempo de cultivo & $\mathrm{meses}$ & 12,00 \\
\hline
\end{tabular}

Comparando os índices zootécnicos registrados na pesquisa com aqueles relatados por Izel et al. (2013), foram constatados resultados semelhantes aos encontrados, indicando que houve consistência nas informações levantadas a campo (Tabela 3).

Tabela 3. Propriedade típica de tambaqui do Amazonas

\begin{tabular}{|c|c|c|c|}
\hline Índices zootécnicos & & $\begin{array}{l}\text { Pesquisa } \\
\text { de campo }\end{array}$ & $\begin{array}{l}\text { Izel et al. } \\
(2013)\end{array}$ \\
\hline & Unidade & -- Qtde -- & -- Qtde -- \\
\hline Área alagada & ha & 3,37 & 1,00 \\
\hline $\begin{array}{l}\text { Densidade de } \\
\text { estocagem }\end{array}$ & peixes.m-2 & 0,62 & 0,70 \\
\hline $\begin{array}{l}\text { Quantidade de peixes } \\
\text { estocados }\end{array}$ & unidade & $20.970,00$ & $7.071,00$ \\
\hline Peso inicial dos peixes & $g$ & 15,00 & 160,00 \\
\hline $\begin{array}{l}\text { Taxa de conversão } \\
\text { alimentar }\end{array}$ & $\mathrm{kg} \cdot \mathrm{kg}^{-1}$ & 1,81 & 2,09 \\
\hline Taxa de sobrevivência & $\%$ & 0,64 & - \\
\hline Peso médio de abate & $\mathrm{kg}$ & 2,67 & 2,62 \\
\hline Produção ano & $\mathrm{kg}$ & $35.747,00$ & $163.064,00$ \\
\hline Produtividade & $\mathrm{kg} h \mathrm{a}^{-1}$ & $10.620,00$ & $18.530,00$ \\
\hline Tempo de cultivo & Meses & 12,00 & 10,00 \\
\hline
\end{tabular}

O investimento considerado para a propriedade típica do Amazonas foi de $\mathrm{R} \$ 224.722,32$ para uma área de 3,37 ha, ou $\mathrm{R} \$ 66.594,17 \mathrm{ha}^{-1}$ (Tabela 4). Outros estudos apontaram os seguintes valores de investimento: $\mathrm{R} \$ 36.173,12$ (SUFRAMA, 2003), R $\$$ 45.000,00 (Izel e Melo, 2004), R\$59.600,00 (Marinho et al., 2009), R\$79.427,27 (Izel et al., 2013) Martin et al. (1995) e Costa (2013) ${ }^{4}$. Os altos valores de implantação dos viveiros estão ligados ao uso maquinário pesado para a retirada da camada orgânica, terraplanagem e nivelamento de solo, confecção dos taludes e das cristas dos tanques, compactação do solo e acabamento dos viveiros. A outra parte da composição deste elevado investimento foi na adequação do sistema hidráulico (abastecimento e drenagem) das pisciculturas.

O custo operacional efetivo foi de $\mathrm{R} \$ 149.226,00$ ou $\mathrm{R} \$ 44.333,33 \mathrm{ha}^{-1}$, ou ainda $\mathrm{R} \$ 4,17 \mathrm{~kg}^{-1}$, composto dos seguintes itens: insumos, mão de obra, imposto, manutenção da estrutura. A ração representou $81,83 \%$ do COE, o item que apresentou elevada taxa de composição nos custos, enquanto a mão de obra representou apenas 5,76\%. O COE representa 73,28\% do CTP. Castro et al. (2002) relataram que os gastos com o consumo de ração, encontram-se diretamente ligados à extensão do ciclo de produção, no qual aponta que, a medida que os peixes estão sob o processo de confinamento, permanece a manutenção com o consumo da ração. Izel e Melo (2004) relataram que, para o estado do Amazonas, a média do custo da ração representa valores menores $(64,20 \%)$.

A composição do custo operacional total [COT], que envolve o COE, a remuneração do produtor e a depreciação do investimento, foi de $\mathrm{R} \$ 4,88 \mathrm{~kg}^{-1}$ (Tabela 5). Os trabalhos de Izel e Melo (2004) e Marinho et al. (2009) relataram COT de $\mathrm{R} \$ 1.32 \mathrm{~kg}^{-1}$ e $\mathrm{R} \$ 3,56 \mathrm{~kg}^{-1}$, respectivamente. No custo total de produção [CTP] considerou-se: o COT, juros sobre o capital e juros sobre o investimento. Comparando com os estudos de Izel e Melo (2004), Marinho et al. (2009) e Izel et al. (2013), o resultado desta pesquisa foi de $\mathrm{R} \$ 5,70 \mathrm{~kg}^{-1} \mathrm{e}$ os demais foram de: $R$ \$2,04 $\mathrm{kg}^{-1}, \mathrm{R} \$ 3,98 \mathrm{~kg}^{-1}$ e $\mathrm{R} \$ 3,76$ $\mathrm{kg}^{-1}$, respectivamente. A Margem Bruta foi de $\mathrm{R} \$ 2,06$ $\mathrm{kg}^{-1}$, o Lucro Operacional de $\mathrm{R} \$ 1,36 \mathrm{~kg}^{-1}$ e o Lucro Líquido de $\mathrm{R} \$ 0,54 \mathrm{~kg}^{-1}$. Comparando com os resultados das pesquisas de Izel e Melo (2004), Marinho et al. (2009) e Izel et al. (2013), os melhores resultados para produção de tambaqui foram encontrados por Izel et al. (2013), cujo lucro foi de 51,02\%, em função da elevada produtividade atingida.

${ }^{4}$ Costa, J.I. da. 2013. Avaliação econômica e participação do plâncton no cultivo de tambaqui em viveiros com diferentes densidades de estocagem. Dissertação (mestrado) - Universidade Estadual Paulista, Centro de Aquicultura. Jesaias Ismael da Costa. Jaboticabal. Disponível em: https:// repositorio.unesp.br/handle/11449/96669. Acesso em: 20 set.2018 
Tabela 4. Investimento propriedade típica de tambaqui do Amazonas

\begin{tabular}{|c|c|c|c|c|c|c|}
\hline Investimento & Unidade & Qtde & Preço & Valor & V. útil & Depr. \\
\hline & & & ------ R\$ ------ & ------ R\$ ------ & - anos - & -- $\mathrm{R} \$ \mathrm{ano}^{-1}$-- \\
\hline Projeto da piscicultura & Unidade & 1,00 & $7.000,00$ & $7.000,00$ & 20 & 350,00 \\
\hline Viveiros escavados & ha & 3,37 & $56.897,80$ & $191.518,00$ & 20 & $9.575,90$ \\
\hline Depósito de ração & container ou $\mathrm{m}^{2}$ & 1,00 & $2.700,00$ & $2.700,00$ & 10 & 270,00 \\
\hline Rede elétrica & unidade & 1,00 & $5.823,00$ & $5.823,00$ & 20 & 291,15 \\
\hline Bomba hidráulica & unidade & 1,00 & $2.780,00$ & $2.780,00$ & 5 & 556,00 \\
\hline Balança digital de 0 - $150 \mathrm{~kg}$ & unidade & 1,00 & 580,00 & 580,00 & 5 & 116,00 \\
\hline Kit de análise de água & unidade & 1,00 & $1.120,00$ & $1.120,00$ & 5 & 224,00 \\
\hline Rede de arrasto de malha de $25 \mathrm{~mm}$ & unidade & 1,00 & $2.320,00$ & $2.320,00$ & 5 & 464,00 \\
\hline Puçá (bag) & unidade & 1,00 & 235,00 & 235,00 & 5 & 47,00 \\
\hline Aeradores & unidade & 4,00 & $1.560,00$ & $6.240,00$ & 5 & $1.248,00$ \\
\hline Outros ( $\%$ do investimento) & $\%$ & 2,00 & $220.316,00$ & $4.406,32$ & 5 & 881,26 \\
\hline Total & & & & $224.722,32$ & & $14.023,31$ \\
\hline
\end{tabular}

Tabela 5. Custo total de produção da propriedade típica de tambaqui do Amazonas

\begin{tabular}{|c|c|c|c|c|c|c|}
\hline Item & Unidade & Qtde & Preço & Valor & Valor & Valor \\
\hline & & & ------ R\$ ------ & ------ R\$ ------ & --- $\mathrm{R} \$ \mathrm{ha}^{-1}$--- & $-\mathrm{R} \$ \mathrm{~kg}^{-1}-$ \\
\hline Insumos de produção & & & & $136.128,36$ & $40.442,17$ & 3,81 \\
\hline Peixes (alevinos) & milheiro & 21,00 & 120,00 & $2.520,00$ & 748,66 & 0,07 \\
\hline Ração & $\mathrm{kg}$ & $64.751,00$ & 1,89 & $122.116,35$ & $36.279,37$ & 3,42 \\
\hline Calcário agrícola & $\mathrm{t}$ & 12,00 & 300,00 & $3.600,00$ & $1.069,52$ & 0,10 \\
\hline Ureia + superfosfato & $\mathrm{kg}$ & 505,00 & 1,00 & 505,00 & 150,03 & 0,01 \\
\hline Energia elétrica & meses & 12,00 & 70,13 & 841,50 & 250,00 & 0,02 \\
\hline Combustível & 1 & 0,00 & 0,00 & 0,00 & 0,00 & 0,00 \\
\hline Medicamentos & $\mathrm{R} \$ \mathrm{ha}^{-1}$ & 1,12 & $2.300,00$ & $2.580,60$ & $2.300,00$ & 0,07 \\
\hline Outros $(\%$ do insumo) & $\%$ & 3,00 & $132.163,45$ & $3.964,90$ & $1.177,93$ & 0,11 \\
\hline Mão de obra & & & & $8.603,10$ & $2.555,88$ & 0,24 \\
\hline Assistência técnica & diária & 12,00 & 150,00 & $1.800,00$ & 534,76 & 0,05 \\
\hline Mão de obra fixa & mês & 12,00 & 491,93 & $5.903,10$ & $1.753,74$ & 0,17 \\
\hline Mão de obra temporária & diária & 10,00 & 50,00 & 500,00 & 148,54 & 0,01 \\
\hline Despesca & diária & 8,00 & 50,00 & 400,00 & 118,84 & 0,01 \\
\hline Impostos & & & & 0,10 & 0,03 & 0,00 \\
\hline Funrural & $\%$ & Isento & & & & \\
\hline Contribuição sindical & $\%$ & Isento & & & & \\
\hline ITR & $\%$ & 0,03 & 3,37 & 0,10 & 0,03 & 0,00 \\
\hline Manutenção da estrutura & & & & $4.494,45$ & $1.335,25$ & 0,13 \\
\hline$\%$ do investimento & $\%$ & 2,00 & $224.722,32$ & $4.494,45$ & $1.335,25$ & 0,13 \\
\hline Custo operacional efetivo [COE] & & & & $149.226,00$ & $44.333,33$ & 4,17 \\
\hline Remuneração do produtor & $\mathrm{R} \$$ & 12,00 & 937,00 & $11.244,00$ & $3.340,46$ & 0,31 \\
\hline Depreciação do investimento & $\mathrm{R} \$$ & 1,00 & $14.023,31$ & $14.023,31$ & $4.166,17$ & 0,39 \\
\hline Custo operacional total [COT] & & & & $174.493,32$ & $51.839,96$ & 4,88 \\
\hline Juros sobre o capital de giro & $\%$ & 12,00 & $149.226,00$ & $17.907,12$ & $5.320,00$ & 0,50 \\
\hline Juros sobre o investimento & $\%$ & 5,00 & $224.722,32$ & $11.236,12$ & $3.338,12$ & 0,31 \\
\hline Custo total de produção [CTP] & & & & $203.636,56$ & $60.498,09$ & 5,70 \\
\hline Receita & $\mathrm{kg}$ & $35.747,00$ & 6,24 & $222.944,80$ & $66.234,34$ & 6,24 \\
\hline Margem bruta & & & & $73.718,79$ & $21.901,01$ & 2,06 \\
\hline Lucro operacional & & & & $48.451,48$ & $14.394,38$ & 1,36 \\
\hline Lucro líquido & & & & $19.308,24$ & $5.736,26$ & 0,54 \\
\hline
\end{tabular}


A análise de cenário de mercado proposta para o lucro líquido apurado em uma propriedade típica de tambaqui do Amazonas foi de $\mathrm{R} \$ 0,54 \mathrm{~kg}^{-1}$ (Tabela 6), considerando o cenário base (adotado no modelo estático), com o preço da ração de $\mathrm{R} \$ 1,89 \mathrm{~kg}^{-1}$ e preço de venda do pescado de $\mathrm{R} \$ 6,24 \mathrm{~kg}^{-1}$ (Tabela 5), A amplitude dos resultados variou entre um lucro líquido de $\mathrm{R} \$ 1,75$ $\mathrm{kg}^{-1}$ até um prejuízo líquido de $\mathrm{R} \$ 1,05 \mathrm{~kg}^{-1}$. Das 25 combinações de preços propostas, 6 combinações $(24 \%)$ foram negativas e 19 combinações $(76 \%)$ foram positivas (Tabela 6).

Tabela 6. Cenários de mercado para o lucro líquido $\left(\mathrm{R} \$ \mathrm{~kg}^{-1}\right)$ na propriedade típica de tambaqui do Amazonas

\begin{tabular}{|c|c|c|c|c|c|c|}
\hline \multirow{6}{*}{ 胥 } & & \multicolumn{5}{|c|}{ Preço de venda $\left(\mathrm{R} \$ \mathrm{~kg}^{-1}\right)$} \\
\hline & & 5,40 & 5,81 & 6,24 & 6,67 & 7,00 \\
\hline & 1,66 & 0,15 & 0,56 & 0,99 & 1,42 & 1,75 \\
\hline & 1,70 & 0,07 & 0,48 & 0,91 & 1,34 & 1,67 \\
\hline & 1,89 & $-0,30$ & 0,11 & 0,54 & 0,97 & 1,30 \\
\hline & 2,07 & $-0,66$ & $-0,26$ & 0,17 & 0,60 & 0,94 \\
\hline & 2,26 & $-1,05$ & $-0,64$ & $-0,21$ & 0,22 & 0,55 \\
\hline
\end{tabular}

A análise de variáveis técnicas para o lucro líquido apurado em uma propriedade típica de tambaqui do Amazonas foi de $\mathrm{R} \$ 0,54 \mathrm{~kg}^{-1}$ (Tabela 7), considerando o cenário base (adotado no modelo estático) com a taxa de conversão alimentar de $1,81 \mathrm{~kg} \mathrm{~kg}^{-1}$ e de sobrevivência de $64 \%$ (Tabela 2). A amplitude dos resultados variou entre um lucro líquido de $\mathrm{R} \$ 1,50 \mathrm{~kg}^{-1}$ até um prejuízo líquido de $\mathrm{R} \$ 1,18 \mathrm{~kg}^{-1}$. Das 25 combinações de preços propostas, 9 combinações $(36 \%)$ foram negativas e 16 $(64 \%)$ foram positivas (Tabela 7 ).

Tabela 7. Cenários de técnicos para o lucro líquido $\left(\mathrm{R} \$ \mathrm{~kg}^{-1}\right)$ na propriedade típica de tambaqui do Amazonas

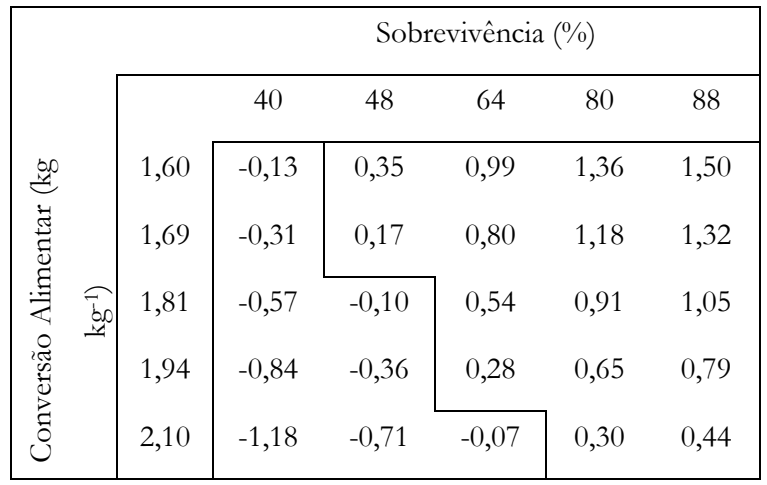

Constatou-se que para o caso do Amazonas, as variáveis técnicas indicaram ter o fator de maior risco, pois apresentou um percentual de $36 \%$ das ocorrências com prejuízo líquido (Tabela 7). Quanto às combinações na quais envolvem preços, deparou com a maior possibilidade de lucro líquido, onde apresentou um percentual de $74 \%$ das ocorrências.

A propriedade típica de Rondônia possui lâmina de água média de 15,02 ha, densidade de estocagem de 0,42 peixes $\mathrm{m}^{-2}$, peso inicial dos alevinos contendo $50 \mathrm{~g}$, taxa de conversão alimentar de 1,66 ( kg de ração kg de peixe $\left.^{-1}\right)$, taxa de sobrevivência final de $61 \%$, peso final de abate de 3,09 kg, produtividade de $7.940 \mathrm{~kg} \mathrm{ha}^{-1} \mathrm{e}$ duração do ciclo de produção de 12 meses (Tabela 8).

A densidade de estocagem obtida na pesquisa (Tabela 9) foi similar à encontrada nos estudos da Embrapa (2015 b; c), porém o peso inicial de alevinos e o peso de abate foram distintos com produtividades próximas de $7.000 \mathrm{~kg} \mathrm{ha}^{-1}$. Outros estudos para esse Estado, como o de Sales (2009), obteve uma conversão alimentar de 1,58 $\mathrm{kg} \mathrm{kg}^{-1}$, e Xavier (2013) obteve uma produtividade de $7.800 \mathrm{~kg} \mathrm{ha}{ }^{-1}$. Segundo Freitas et al. (2015), os viveiros de produção de tambaquis em Urupá - RO apresentaram peso do abate superior a $3,0 \mathrm{~kg}$ com ciclo de produção de 12 meses.

O investimento considerado para a propriedade típica de Rondônia foi de R \$49.080,19 ha $\mathrm{ha}^{-1}$ (Tabela 10). Outros estudos indicaram investimentos de $\mathrm{R} \$ 33.576,72 \mathrm{ha}^{-1}$ (Suframa, 2003), R\$ 33.615,00 ha-1 (Souza, 2014) e R\$ 54.666,67 ha $^{-1}$ (Freitas et al., 2015). As diferenças entre os valores de investimento, podem estar relacionados aos preços praticados na época de cada pesquisa, as condições do local de implementação e da escala do projeto de piscicultura adotado.

O custo operacional efetivo de todos os investimentos realizados na propriedade foi de $\mathrm{R} \$ 26.711,99 \mathrm{ha}^{-1}$, ou seja, $\mathrm{R} \$ 3,36 \mathrm{~kg}^{-1}$ (Tabela 11). A ração representou 76,44\% do $\mathrm{COE}$, enquanto a mão de obra representou apenas 9,06\%. O COE representou 73,15\% do CTP. Loose et al. (2014), EMBRAPA (2015) e Freitas et al. (2015) calcularam a participação da ração no COE encontrando valores de $72,73 \%, 84,39 \%$ e $84,77 \%$, respectivamente. Constando que a ração foi o componente de maior impacto composição do COE.

O COT da propriedade títpica de tambaqu de Rondônia foi de $\mathrm{R} \$ 30.857,99 \mathrm{ha}^{-1}, \mathrm{R} \$ 3,89 \mathrm{~kg}^{-1}$, valores estes inferiores aos apresentados nos trabalhos realizados pela Embrapa (2015) em Ariquemes e Pimenta Bueno, $\mathrm{R} \$ 4,08 \mathrm{~kg}^{-1} \mathrm{e} \mathrm{R} \$ 5,18 \mathrm{~kg}^{-1}$, respectivamente. O custo total de produção foi de $\mathrm{R} \$ 36.516,73 \mathrm{ha}^{-1}$ ou $\mathrm{R} \$ 4,60$ $\mathrm{kg}^{-1}$. Souza (2014) por sua vez obteve o CTP de R $\$ 2,73$ $\mathrm{kg}^{-1}$; Loose et al. (2014), R\$ 3,76 $\mathrm{kg}^{-1}$; e, EMBRAPA (2015), encontraram $\mathrm{R} \$ 4,66 \mathrm{~kg}^{-1}$ em Ariquemes e $\mathrm{R} \$$ $8,08 \mathrm{~kg}^{-1}$ Pimenta Bueno. A rentabilidade obtida em Rondônia foi de uma margem bruta de $\mathrm{R} \$ 1,48 \mathrm{~kg}^{-1}$, com o lucro operacional de $\mathrm{R} \$ 0,96 \mathrm{~kg}^{-1}$ e lucro líquido de $\mathrm{R} \$ 0,25 \mathrm{~kg}^{-1}$. 
Tabela 8. Propriedade típica de tambaqui de Rondônia

\begin{tabular}{lrr}
\hline Índices zootécnicos & Unidade & Qtde \\
\hline Área alagada & ha & 15,02 \\
Densidade de estocagem & peixes m ${ }^{-2}$ & 0,42 \\
Quantidade de peixes estocados & unidade & $63.252,00$ \\
Peso inicial dos peixes & $\mathrm{g}$ & 50,00 \\
Taxa de conversão alimentar & $\mathrm{kg} \mathrm{kg}^{-1}$ & 1,66 \\
Taxa de sobrevivência & $\% \mathrm{o}$ & 0,61 \\
Peso médio de abate & $\mathrm{kg}$ & 3,09 \\
Produção ano & $\mathrm{kg}$ & $119.297,00$ \\
Produtividade & $\mathrm{kg} \mathrm{ha}^{-1}$ & $7.940,00$ \\
Tempo de cultivo & meses & 12,00 \\
\hline
\end{tabular}

Tabela 9. Propriedade típica de tambaqui de Rondônia

\begin{tabular}{|c|c|c|c|c|}
\hline Índices zootécnicos & & $\begin{array}{c}\text { Pesquisa } \\
(2017)\end{array}$ & $\begin{array}{c}\text { Ariquemes } \\
\text { (2015) }\end{array}$ & $\begin{array}{c}\text { P. Bueno } \\
\text { (2015) }\end{array}$ \\
\hline & -- Unidade -- & ----- Qtde ----- & -------- Qtde -------- & -------- Qtde -------- \\
\hline Área alagada & ha & 15,02 & 5,00 & 0,50 \\
\hline Densidade de estocagem & peixes $\mathrm{m}^{-2}$ & 0,42 & 0,40 & 0,33 \\
\hline Quantidade de peixes estocados & unidade & $63.252,00$ & $20.000,00$ & $1.650,00$ \\
\hline Peso inicial dos peixes & $g$ & 50,00 & 2,00 & 4,00 \\
\hline Taxa de conversão alimentar & $\mathrm{kg} \mathrm{kg}^{-1}$ & 1,66 & 1,55 & 1,69 \\
\hline Taxa de sobrevivência & $\%$ & 0,64 & - & 0,91 \\
\hline Peso médio de abate & $\mathrm{kg}$ & 3,09 & 2,50 & 1,60 \\
\hline Produção ano & $\mathrm{kg}$ & $119.297,00$ & $35.000,00$ & $2.400,00$ \\
\hline Produtividade & $\mathrm{kg} h \mathrm{a}^{-1}$ & $7.940,00$ & $7.000,00$ & $4.800,00$ \\
\hline Tempo de cultivo & meses & 12,00 & 13,80 & 11,50 \\
\hline
\end{tabular}

Tabela 10. Investimento propriedade típica de tambaqui de Rondônia

\begin{tabular}{|c|c|c|c|c|c|c|}
\hline Investimento & Unidade & Qtde & Preço & Valor & V. útil & Depr. \\
\hline & & & ------ R\$ ------ & ----- R\$ ----- & - anos - & -- $\mathrm{R} \$ \mathrm{ano}^{-1}$-- \\
\hline Projeto da piscicultura & unidade & 1,00 & $10.000,00$ & $10.000,00$ & 20 & 500,00 \\
\hline Viveiros escavados & ha & 15,02 & $42.440,49$ & $637.640,00$ & 20 & $31.882,00$ \\
\hline Depósito de ração & container ou $\mathrm{m}^{2}$ & 3,00 & $2.700,00$ & $8.100,00$ & 10 & 810,00 \\
\hline Rede elétrica & unidade & 3,00 & $6.200,00$ & $18.600,00$ & 20 & 930,00 \\
\hline Bomba hidráulica & unidade & 4,00 & $2.890,00$ & $11.560,00$ & 5 & $2.312,00$ \\
\hline Balança digital de 0 - $150 \mathrm{~kg}$ & unidade & 3,00 & 518,00 & $1.554,00$ & 5 & 310,80 \\
\hline Kit de análise de água & unidade & 5,00 & 980,00 & $4.900,00$ & 5 & 980,00 \\
\hline Rede de arrasto de malha de $25 \mathrm{~mm}$ & unidade & 4,00 & $3.800,00$ & $15.200,00$ & 5 & $3.040,00$ \\
\hline Puçá (bag) & unidade & 2,00 & 235,00 & 470,00 & 5 & 94,00 \\
\hline Aeradores & unidade & 1,00 & $15.000,00$ & $15.000,00$ & 5 & $3.000,00$ \\
\hline Outros ( $\%$ do investimento) & $\%$ & 2,00 & $708.024,00$ & $14.160,48$ & 5 & $2.832,10$ \\
\hline Total & & & & $737.184,48$ & & $46.690,90$ \\
\hline
\end{tabular}


Tabela 11. Custo total de produção da propriedade típica de tambaqui de Rondônia

\begin{tabular}{|c|c|c|c|c|c|c|}
\hline Item & Unidade & Qtde & Preço & Valor & Valor & Valor \\
\hline & & & ------ R\$ ------ & ------ R\$ ------ & --- $\mathrm{R} \$ \mathrm{ha}^{-1}---$ & - $\mathrm{R} \$ \mathrm{~kg}^{-1}$ - \\
\hline Insumos de produção & & & & $350.242,54$ & $23.311,69$ & 2,94 \\
\hline Peixes (alevinos) & milheiro & 64,00 & 100,00 & $6.400,00$ & 425,98 & 0,05 \\
\hline Ração & $\mathrm{kg}$ & $197.476,00$ & 1,55 & $306.759,50$ & $20.417,51$ & 2,57 \\
\hline Calcário agrícola & $\mathrm{t}$ & 31,00 & 300,00 & $9.300,00$ & 619,00 & 0,08 \\
\hline Ureia + superfosfato & $\mathrm{kg}$ & $1.202,00$ & 1,00 & $1.202,00$ & 80,00 & 0,01 \\
\hline Energia elétrica & meses & 12,00 & 100,16 & $1.201,95$ & 80,00 & 0,01 \\
\hline Combustível & 1 & 360,00 & 3,20 & $1.152,00$ & 76,68 & 0,01 \\
\hline Medicamentos & $\mathrm{R} \$ \mathrm{ha}^{-1}$ & 5,01 & $2.800,00$ & $14.022,71$ & 933,33 & 0,12 \\
\hline Outros ( $\%$ do insumo) & $\%$ & 3,00 & $340.146,15$ & $10.204,38$ & 679,19 & 0,09 \\
\hline Mão de obra & & & & $36.343,20$ & $2.418,96$ & 0,30 \\
\hline Assistência técnica & diária & 12,00 & 180,00 & $2.160,00$ & 143,77 & 0,02 \\
\hline Mão de obra fixa & mês & 24,00 & $1.311,80$ & $31.483,20$ & $2.095,48$ & 0,26 \\
\hline Mão de obra temporária & diária & 30,00 & 45,00 & $1.350,00$ & 89,85 & 0,01 \\
\hline Despesca & diária & 30,00 & 45,00 & $1.350,00$ & 89,85 & 0,01 \\
\hline Impostos & & & & 0,45 & 0,03 & 0,00 \\
\hline Funrural & $\%$ & Isento & & & & \\
\hline Contribuição sindical & $\%$ & Isento & & & & \\
\hline ITR & $\%$ & 0,03 & 15,02 & 0,45 & 0,03 & 0,00 \\
\hline Manutenção da estrutura & & & & $14.743,69$ & 981,32 & 0,12 \\
\hline$\%$ do investimento & $\%$ & 2,00 & $737.184,48$ & $14.743,69$ & 981,32 & 0,12 \\
\hline Custo operacional efetivo [COE] & & & & $401.329,88$ & $26.711,99$ & 3,36 \\
\hline Remuneração do produtor & $\mathrm{R} \$$ & 12,00 & $1.300,00$ & $15.600,00$ & $1.038,32$ & 0,13 \\
\hline Depreciação do investimento & $\mathrm{R} \$$ & 1,00 & $46.690,90$ & $46.690,90$ & $3.107,69$ & 0,39 \\
\hline Custo operacional total [COT] & & & & $463.620,78$ & $30.857,99$ & 3,89 \\
\hline Juros sobre o capital de giro & $\%$ & 12,00 & $401.329,88$ & $48.159,59$ & $3.205,44$ & 0,40 \\
\hline Juros sobre o investimento & $\%$ & 5,00 & $737.184,48$ & $36.859,22$ & $2.453,30$ & 0,31 \\
\hline Custo total de produção [CTP] & & & & $548.639,58$ & $36.516,73$ & 4,60 \\
\hline Receita & $\mathrm{kg}$ & $119.297,00$ & 4,85 & $578.391,76$ & $38.497,00$ & 4,85 \\
\hline Margem bruta & & & & $177.061,88$ & $11.785,01$ & 1,48 \\
\hline Lucro operacional & & & & $114.770,99$ & $7.639,01$ & 0,96 \\
\hline Lucro líquido & & & & $29.752,18$ & $1.980,27$ & 0,25 \\
\hline
\end{tabular}

Considerando o preço de venda do peixe de $\mathrm{R} \$ 4,85$ $\mathrm{kg}^{-1}$ e o preço da ração de $\mathrm{R} \$ 1,55 \mathrm{~kg}^{-1}$ (Tabela 11), a análise de cenário de mercado para lucro líquido em uma propriedade típica de produção de tambaqui em Rondônia apresentou variação entre um lucro líquido de $\mathrm{R} \$ 0,67 \mathrm{~kg}^{-1}$ até um prejuízo líquido de $\mathrm{R} \$ 0,01 \mathrm{~kg}^{-1}$. Das 25 combinações de preços propostas duas $(8 \%)$ foram negativas e 23 (92\%) positivas (Tabela12).

$\mathrm{Na}$ segunda análise, quanto os parâmetros técnicos para a propriedade típica de tampaqui em Rondônia, a amplitude dos resultados varia entre um lucro líquido de $R \$ 0,93 \mathrm{~kg}^{-1}$ até um prejuízo líquido de $\mathrm{R} \$ 0,09 \mathrm{~kg}^{-1}$, considerando os parâmetros bases (Tabela 8). Das 25 combinações de preços propostas 9 (36\%) foram negativas e $16(64 \%)$ positivas. Constatou-se que as variáveis técnicas foram os fatores de maior risco, em que 36\% das ocorrências apresentaram prejuízo líquido (Tabela
13). A maioria das combinações de preços apresentaram possibilidade de lucro líquido ( $92 \%$ das ocorrências).

Tabela 12. Cenários de mercado para o lucro líquido $\left(\mathrm{R} \$ \mathrm{~kg}^{-1}\right)$ na propriedade típica de tambaqui de Rondônia

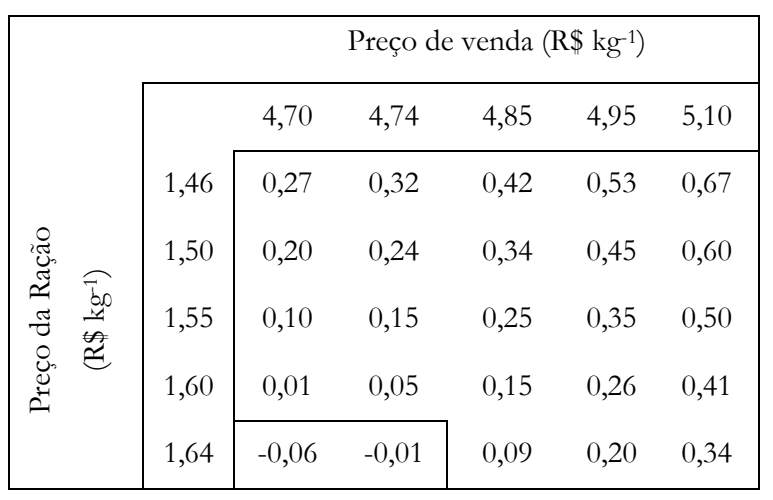


Tabela 13. Cenários de técnicos para o lucro líquido $\left(\mathrm{R} \$ \mathrm{~kg}^{-1}\right)$ na propriedade típica de tambaqui de Rondônia

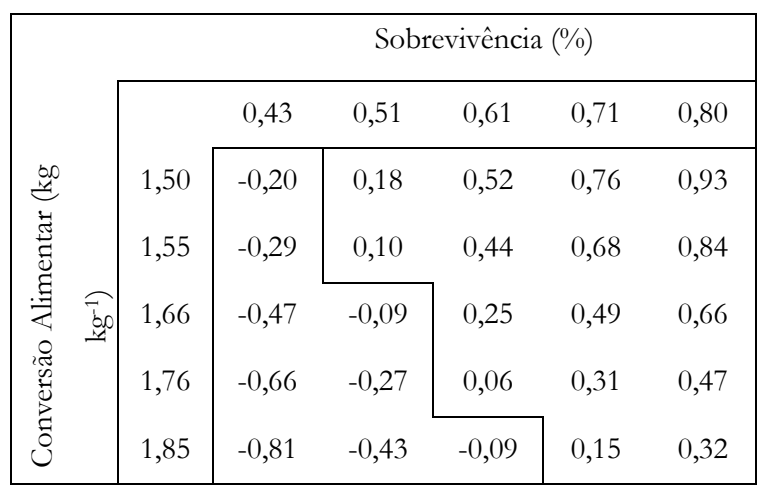

A propriedade típica de Roraima para a produção do tambaqui apresenta uma lâmina de água média foi de 77,70 ha de viveiro escavado; a densidade de estocagem de 0,39 peixes $\mathrm{m}^{-2}$; peso inicial dos alevinos contendo 50 g; a taxa de conversão alimentar de 1,78 (kg de ração $\mathrm{kg}$ de peixe $^{-1}$ ); a taxa de sobrevivência final de $72 \%$; o peso final de abate de $2,99 \mathrm{~kg}$; a produtividade de 8.425 $\mathrm{kg} \mathrm{ha}{ }^{-1}$; e a duração do ciclo de produção de 12 meses (Tabela 14).

Comparando os índices zootécnicos da pesquisa com o estudo realizado pelo SEBRAE (2008) e Pereira et al. (2013), observou resultados semelhantes aos encontrados, indicando que houve consistência nas informações levantadas a campo (Tabela 15).

Tabela 14. Propriedade típica de tambaqui de Roraima

\begin{tabular}{lcr}
\hline Índices zootécnicos & Unidade & Qtde \\
\hline Área alagada & ha & 77,70 \\
Densidade de estocagem & peixes m-2 & 0,39 \\
Quantidade de peixes estocados & unidade & $303.276,00$ \\
Peso inicial dos peixes & $\mathrm{g}$ & 50,00 \\
Taxa de conversão alimentar & $\mathrm{kg} \mathrm{kg}^{-1}$ & 1,78 \\
Taxa de sobrevivência & $\%$ ó & 0,72 \\
Peso médio de abate & $\mathrm{kg}^{-2}$ & 2,99 \\
Produção ano & $\mathrm{kg}^{-1}$ & $654.564,00$ \\
Produtividade & $\mathrm{kg} \mathrm{ha}^{-1}$ & $8.425,00$ \\
Tempo de cultivo & meses & 12,00 \\
\hline
\end{tabular}

Tabela 15. Propriedade típica de tambaqui em Roraima

\begin{tabular}{|c|c|c|c|c|}
\hline Índices zootécnicos & & Pesquisa de campo & $\begin{array}{c}\text { SEBRAE - RR } \\
\text { (2008) }\end{array}$ & $\begin{array}{c}\text { Pereira et al. } \\
(2013)\end{array}$ \\
\hline & --- Unidade --- & ------- Qtde ------- & -------- Qtde -------- & ---------- Qtde ---------- \\
\hline Área alagada & ha & 77,70 & 1,00 & 100,00 \\
\hline Densidade de estocagem & peixes $\mathrm{m}^{-2}$ & 0,39 & 0,26 & 0,40 \\
\hline Quantidade de peixes estocados & unidade & $303.276,00$ & $2.600,00$ & - \\
\hline Peso inicial dos peixes & g & 50,00 & 80,00 & - \\
\hline Taxa de conversão alimentar & $\mathrm{kg} \mathrm{kg}^{-1}$ & 1,78 & 1,80 & 1,70 \\
\hline Taxa de sobrevivência & $\%$ & 0,72 & - & - \\
\hline Peso médio de abate & $\mathrm{kg}$ & 2,99 & 3,00 & - \\
\hline Produção ano & $\mathrm{kg}$ & $654.564,00$ & $7.500,00$ & - \\
\hline Produtividade & $\mathrm{kg} \mathrm{ha}^{-1}$ & $8.425,00$ & $7.500,00$ & - \\
\hline Tempo de cultivo & meses & 12,00 & 12,00 & 12,00 \\
\hline
\end{tabular}

Os índices zootécnicos dos estudos indicaram uma baixa densidade de estocagem. A taxa de conversão alimentar dos tambaquis cultivados em Roraima apresentou um valor de $1,78 \mathrm{~kg} \mathrm{~kg}^{-1}$, semelhante aos parâmetros dos estudos realizados por Pereira et al. (2013) que variaram de $1,7 \mathrm{~kg} \mathrm{~kg}^{-1}$ a $1,97 \mathrm{~kg} \mathrm{~kg}^{-1}$. O peso médio de abate para o mercado de Manaus foi semelhante ao resultado da pesquisa do SEBRAE (2008). A produtividade inferior à $9 \mathrm{t} \mathrm{ha}^{-1}$ foi justificada por
Pereira et al. (2013) pela qualidade da água como fator limitante, pois $35,1 \%$ das propriedades eram abastecidas pelo lençol freático e 48,6\% das propriedades eram abastecidas por outras fontes hídricas (igarapé - 21,6\% e chuva 8,1\%) ('Tabela 15).

$\mathrm{O}$ investimento da área por hectare considerado para a propriedade típica de Roraima foi de $\mathrm{R} \$ 43.777,18$ (Tabela 16). Em Suframa (2003), esse investimento foi de $\mathrm{R} \$ 35.855,15$ em valores nominais. 
Tabela 16. Investimento propriedade típica de tambaqui de Roraima

\begin{tabular}{|c|c|c|c|c|c|c|}
\hline Investimento & Unidade & Qtde & Preço & Valor & V. útil & Depr. \\
\hline & & & ----- R\$ ----- & ----- R\$ ----- & - anos - & -- $\mathrm{R} \$ \mathrm{ano}^{-1}$-- \\
\hline Projeto da piscicultura & unidade & 1,00 & $10.000,00$ & $10.000,00$ & 20 & 500,00 \\
\hline Viveiros escavados & ha & 77,70 & $40.422,58$ & $3.140 .700,00$ & 20 & $157.035,00$ \\
\hline Depósito de ração & container ou $\mathrm{m}^{2}$ & 60,00 & 230,00 & $13.800,00$ & 10 & $1.380,00$ \\
\hline Rede elétrica & unidade & 8,00 & $5.200,00$ & $41.600,00$ & 20 & $2.080,00$ \\
\hline Bomba hidráulica & unidade & 7,00 & $2.983,00$ & $20.881,00$ & 5 & $4.176,20$ \\
\hline Balança digital de 0 - $150 \mathrm{~kg}$ & unidade & 4,00 & 520,00 & $2.080,00$ & 5 & 416,00 \\
\hline Kit de análise de água & unidade & 10,00 & 930,00 & $9.300,00$ & 5 & $1.860,00$ \\
\hline Rede de arrasto de malha de $25 \mathrm{~mm}$ & unidade & 5,00 & $4.000,00$ & $20.000,00$ & 5 & $4.000,00$ \\
\hline Puçá (bag) & unidade & 4,00 & 235,00 & 940,00 & 5 & 188,00 \\
\hline Aeradores & unidade & 2,00 & $38.500,00$ & $77.000,00$ & 5 & $15.400,00$ \\
\hline Outros ( $\%$ do investimento) & $\%$ & 2,00 & $3.259 .301,00$ & $65.186,02$ & 5 & $13.037,20$ \\
\hline Total & & & & $3.401 .487,02$ & & $200.072,40$ \\
\hline
\end{tabular}

O custo operacional efetivo foi de $\mathrm{R} \$ 32.474,46 \mathrm{ha}^{-1}$, ou R\$3,85 $\mathrm{kg}^{-1}$, composto por insumos, mão de obra, imposto, manutenção da estrutura. $\mathrm{O}$ preço da ração representou $84,43 \%$ do $\mathrm{COE}$, enquanto a mão de obra representou apenas $3,25 \%$. O COE representou $77,59 \%$ do CTP. O custo operacional total [COT], composto pela somatória do COE e remuneração do produtor depreciação do investimento, foi de $\mathrm{R} \$ 4,25 \mathrm{~kg}^{-1}$. O CTP considerando: o COT, juros sobre o capital e juros sobre o investimento, foi de $\mathrm{R} \$ 4,97 \mathrm{~kg}^{-1}$ (Tabela 17).

Tabela 17. Custo total de produção da propriedade típica de tambaqui de Roraima

\begin{tabular}{|c|c|c|c|c|c|c|}
\hline Item & Unidade & Qtde & Preço & Valor & Valor & Valor \\
\hline & & & ----- R\$ ----- & ------ R\$ ------ & --- R\$ ha-1 --- & --- $\mathrm{R} \$ \mathrm{~kg}^{-1}$--- \\
\hline Insumos de produção & & & & $2.372 .915,54$ & $30.540,76$ & 3,63 \\
\hline Peixes (alevinos) & milheiro & 304 & 150,00 & $45.600,00$ & 586,90 & 0,07 \\
\hline Ração & $\mathrm{kg}$ & 1.165 .124 & 1,83 & $2.130 .467,16$ & $27.420,32$ & 3,25 \\
\hline Calcário agrícola & $\mathrm{t}$ & 195 & 300,00 & $58.500,00$ & 752,93 & 0,09 \\
\hline Ureia + superfosfato & $\mathrm{kg}$ & 4.662 & 1,00 & $4.662,00$ & 60,00 & 0,01 \\
\hline Energia elétrica & meses & 12 & $1.100,70$ & $13.208,43$ & 170,00 & 0,02 \\
\hline Combustível & 1 & 720 & 3,10 & $2.232,00$ & 28,73 & 0,00 \\
\hline Medicamentos & $\mathrm{R} \$ \mathrm{ha}^{-1}$ & 25,90 & $2.030,00$ & $52.574,74$ & 676,67 & 0,08 \\
\hline Outros ( $\%$ do insumo) & $\%$ & 3 & $2.189 .040,07$ & $65.671,20$ & 845,23 & 0,10 \\
\hline Mão de obra & & & & $82.206,40$ & $1.058,04$ & 0,13 \\
\hline Assistência técnica & diária & 12 & 170,00 & $2.040,00$ & 26,26 & 0,00 \\
\hline Mão de obra fixa & mês & 48 & $1.311,80$ & $62.966,40$ & 810,41 & 0,10 \\
\hline Mão de obra temporária & diária & 80 & 50,00 & $4.000,00$ & 51,48 & 0,01 \\
\hline Despesca & diária & 264 & 50,00 & $13.200,00$ & 169,89 & 0,02 \\
\hline Impostos & & & & 5,44 & 0,07 & 0,00 \\
\hline Funrural & $\%$ & Isento & & & & \\
\hline Contribuição sindical & $\%$ & Isento & & & & \\
\hline ITR & $\%$ & 0,07 & 77,70 & 5,44 & 0,07 & 0,00 \\
\hline Manutenção da estrutura & & & & $68.029,74$ & 875,58 & 0,10 \\
\hline$\%$ do investimento & $\%$ & 2 & $3.401 .487,02$ & $68.029,74$ & 875,58 & 0,10 \\
\hline Custo operacional efetivo [COE] & & & & $2.523 .157,12$ & $32.474,46$ & 3,85 \\
\hline Remuneração do produtor & $\mathrm{R} \$$ & 12 & $4.630,00$ & $55.560,00$ & 715,09 & 0,08 \\
\hline Depreciação do investimento & $\mathrm{R} \$$ & 1 & $200.072,40$ & $200.072,40$ & $2.575,04$ & 0,31 \\
\hline Custo operacional total [COT] & & & & $2.778 .789,53$ & $35.764,59$ & 4,25 \\
\hline Juros sobre o capital de giro & $\%$ & 12 & $2.523 .157,12$ & $302.778,85$ & $3.896,93$ & 0,46 \\
\hline Juros sobre o investimento & $\%$ & 5 & $3.401 .487,02$ & $170.074,35$ & $2.188,95$ & 0,26 \\
\hline Custo total de produção [CTP] & & & & $3.251 .642,73$ & $41.850,48$ & 4,97 \\
\hline Receita & & 654.564 & 5,91 & $3.868 .471,86$ & $49.789,42$ & 5,91 \\
\hline Margem bruta & & & & $1.345 .314,73$ & $17.314,96$ & 2,06 \\
\hline Lucro operacional & & & & $1.089 .682,33$ & $14.024,83$ & 1,66 \\
\hline Lucro líquido & & & & $616.829,12$ & $7.938,94$ & 0,94 \\
\hline
\end{tabular}


A relação aos indicadores de viabilidade econômica, nos quais foram calculados na pesquisa, apresentaram a margem bruta de $\mathrm{R} \$ 2,06 \mathrm{~kg}^{-1}$, o lucro operacional de $\mathrm{R} \$$ 1,66 $\mathrm{kg}^{-1}$ e o Lucro Líquido de $\mathrm{R} \$ 0,94 \mathrm{~kg}^{-1}$.

A primeira análise de cenário proposta para a propriedade típica de tambaqui de Roraima apresentou uma amplitude dos resultados entre um lucro líquido de $\mathrm{R} \$ 1,60 \mathrm{~kg}^{-1}$ até o líquido de $\mathrm{R} \$ 0,21 \mathrm{~kg}^{-1}$. Das 25 combinações de preços propostas $25(100 \%)$ positivas (Tabela 18).

Tabela 18. Cenários de mercado para o lucro líquido $\left(\mathrm{R} \$ \mathrm{~kg}^{-1}\right)$ na propriedade típica de tambaqui de Roraima

\begin{tabular}{|c|c|c|c|c|c|c|}
\hline \multirow{6}{*}{ 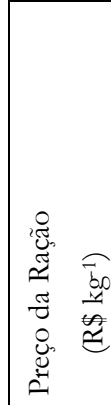 } & & \multicolumn{5}{|c|}{ Preço de venda $\left(\mathrm{R} \$ \mathrm{~kg}^{-1}\right)$} \\
\hline & & 5,50 & 5,71 & 5,91 & 6,11 & 6,30 \\
\hline & 1,70 & 0,80 & 1,00 & 1,21 & 1,41 & 1,60 \\
\hline & 1,75 & 0,69 & 0,89 & 1,10 & 1,30 & 1,49 \\
\hline & 1,83 & 0,53 & 0,74 & 0,94 & 1,14 & 1,33 \\
\hline & 1,91 & 0,38 & 0,59 & 0,79 & 0,99 & 1,18 \\
\hline & 1,99 & 0,21 & 0,42 & 0,62 & 0,82 & 1,01 \\
\hline
\end{tabular}

$\mathrm{Na}$ segunda análise quanto aos cenários técnicos para o lucro líquido na propriedade típica de tambaqui de Roraima, a amplitude dos resultados variou entre um lucro líquido de $\mathrm{R} \$ 2,05 \mathrm{~kg}^{-1}$ até o líquido de $\mathrm{R} \$ 0,09 \mathrm{~kg}^{-1}$. Das 25 combinações de preços propostas $25(100 \%)$ positivas (Tabela 19).

Tabela 19. Cenários de técnicos para o lucro líquido $\left(\mathrm{R} \$ \mathrm{~kg}^{-1}\right)$ na propriedade típica de tambaqui de Roraima

\begin{tabular}{|c|c|c|c|c|c|c|}
\hline & & & Sol & rivênc & & \\
\hline & & 0,50 & 0,59 & 0,72 & 0,86 & 0,97 \\
\hline bo & 1,40 & 1,15 & 1,42 & 1,72 & 1,93 & 2,05 \\
\hline 苞 & 1,65 & 0,64 & 0,92 & 1,22 & 1,42 & 1,55 \\
\hline 学 & 1,78 & 0,37 & 0,64 & 0,94 & 1,15 & 1,27 \\
\hline 过 & 1,91 & 0,09 & 0,37 & 0,67 & 0,87 & 1,00 \\
\hline 0 & 1,90 & 0,12 & 0,40 & 0,70 & 0,90 & 1,03 \\
\hline
\end{tabular}

Constatou-se que para o caso de Roraima as variáveis técnicas e preço apresentaram 100\% das ocorrências que possibilitaram o lucro líquido. Não apresentou inviabilidade técnica decorrente das oscilações ao longo do tempo.
Apesar o estado do Amazonas ser o principal mercado consumidor dos tambaquis produzidos na região Norte, o sistema de produção adotado no estado apresentou os maiores riscos de insucesso quando comparados aos demais estados.

\section{Conclusão}

A análise do risco de preço e variavéis técnicas em função lucro líquido demonstra que o estado de Roraima apresenta o menor risco de insucesso considerando os dados da amostra levantada a campo. Seguido de Rondônia, cujo custo de produção competitivo é limitado por uma logística de entrega do peixe bastante complexa. E, finalmente, o Amazonas, destino final de boa parte da produção de tambaquis da região norte, mas cuja piscicultura apresenta os maiores riscos de insucesso.

\section{Referências}

Affonso, E.G.; Barros, F.P.; Brasil, E.M.; Tavares-Dias, M.; Ono, E.A. 2009. Indicadores fisiológicos de estresse em peixes expostos ao peróxido de hidrogênio (H2O2). In: Tavares-Dias, M. (Org.). Manejo e sanidade de peixes em cultivo. Embrapa Amapá: Macapá. p.346-360.

Albuquerque, U.P.; Lucena, R.F.P.; Alencar, N.L. 2008. Métodos e técnicas para coleta de dados etnobotânicos. In: Albuquerque, U.P.; Lucena, R.F.P.; Cunha, L.V.F.C. da. Métodos e técnicas na pesquisa etnobotânica. Recife: COMUNIGRAF/ NUPEEA. cap.2, p.41-72.

Araújo-Lima, C.; Goulding, M. 1998. Os frutos do tambaqui: ecologia, conservação e cultivo na Amazônia. Tefé, AM: Sociedade Civil de Mamirauá. 186 p.

Barone, R.S.C.; Lorenz, E.K.; Sonoda, D.Y.; Cyrino, J.E.P. 2017. Fish and fishery products trade in brazil, 2005 to 2015: A review of available data and trends. Scientia Agrícola: 74(5): 417-424.

Brasil. 2013. Ministério da Pesca e Aquicultura. Boletim estatístico da pesca e aquicultura. Brasília, DF, $60 \mathrm{p}$

Brasil. 2015. Ministério da Pesca e Aquicultura. Plano de Desenvolvimento da Aquicultura Brasileira - 2015/2020, Brasília.

Campos, J.L; Ono, E.A; Istchuk, P.I. 2015. A Cadeia de Produção e o Preço do Tambaqui. Panorama da Aqüicultura, maio, junho 2015.

Castro, A.L.; Souza, N.H.; Barros, L.C.G. 2002. Avaliação do sistema de produção de Tambaqui intensivo em viveiro de terra com aeração. Aracajú: Embrapa Tabuleiros Costeiros, 2002. 4 p. (Comunicado Técnico, 4). Comunicado técnico 09-MAPA. 4 p.

Conselho Estadual do Meio Ambiente do Amazonas [CEMAAM]. 2008. Regularização ambiental de tanques, viveiros, barragens, pequenos reservatórios, canais de igarapés e tanques rede destinados para a Aquicultura do estado do Amazonas. Manaus, Resolução nº 01/08 - de 03 julho de 2008.

Dairiki, J.K.; Silva, T.B.A. 2011. Revisão de literatura: Exigências nutricionais do tambaqui - Compilações de trabalhos, formulação de ração adequada e desafios futuros. Manaus: 
Embrapa Amazônia Ocidental. Documentos; 91, p. 44. Serie III. Disponível em: <http://www.infoteca.cnptia.embrapa. br/handle/doc/931300>. Acesso em: 12 Jan. 2016.

Empresa Brasileira de Pesquisa Agropecuária [EMBRAPA] Amazônia Ocidental. 2002. Critérios para seleção de local para piscicultura em tanques-rede na Amazônia. MANAUS: Embrapa Amazônia Ocidental. 13p. Embrapa Amazônia Ocidental, Documento 22. ISSN 1517-3135;110.

Empresa Brasileira de Pesquisa Agropecuária [EMBRAPA] Amazônia Ocidental. 2013. Plano estratégico da Embrapa Amazônia Ocidental para Aquicultura. MANAUS: Embrapa Amazônia Ocidental. 93p.: il. Color. - (Documentos/ Embrapa Amazônia Ocidental, ISSN 1517-3135; 110).

Empresa Brasileira de Pesquisa Agropecuária Amazônia Oriental [EMBRAPA]. 2015a. Revista de Agropecuária da Embrapa Amazônia Oriental (AGRO FOCO) - Ano I - no 2 - ago. 2015.

Empresa Brasileira de Pesquisa Agropecuária Amazônia Oriental [EMBRAPA]. 2015b. Informativo Campo Futuro Ariquemes/RO. Edição 17.

Empresa Brasileira de Pesquisa Agropecuária Amazônia Oriental [EMBRAPA]. 2015c. Informativo Campo Futuro Pimenta Bueno/RO. Edição 18.

Fim, J.D.I.; Guimarães, S.F.; Storfi Filho, A.; Bobote, A.G.; Nobre Filho, G.R. 2009. Manual de criação de matrinxã (Brycon amazonicus) em canais de igarapés. Manaus: INPA. $46 \mathrm{p}$.

Freitas, C.E.C. 2003. Recursos pesqueiros amazônicos: status da exploração pesqueira e perspectivas de desenvolvimento do extrativismo e da piscicultura. In: Melo, A. F. (Org.). O futuro da Amazônia: dilemmas, oportunidades e desafios no Limiar do século XXI. Brasília: Instituto Edivaldo Lodi. Ministério do desenvolvimento, Indústria e Comércio, v.1, p.101 - 130 .

Freitas, C.O; Rocha, C.T; Loose, C.E; Leite, E.S; Silva, J de S. 2015. Gestão de custo e viabilidade de implantação de piscicultura no Município de Urupá em Rondônia, Amazônia, Brasil. XXII Congresso Brasileiro de Custos - Foz do Iguaçu, PR, Brasil, 11 a 13 de novembro de 2015.

Gandra, A.L. 2010. O Mercado do Pescado da Região Metropolitana de Manaus. Infopesca. Proyecto Mejoramiento del Acceso a los Mercados de Productos Pesqueros y Acuícolas de la Amazonia, CFC/FAO/INFOPESCA, CFC/ FSCFT/28. 91p.

Instituto Brasileiro de Geografia e Estatística [IBGE]. Produção da aquicultura. Disponível em: <http://www.sidra.ibge.gov.br/bda/tabela/listabl. asp? $\mathrm{c}=3940 \& \mathrm{n}=0 \& \mathrm{u}=0 \& \mathrm{z}=\mathrm{p} \& \mathrm{o}=27 \& \mathrm{i}=\mathrm{P}>$. Acesso em: 24 fev 2015.

Instituto de Proteção Ambiental do Amazonas [IPAAM]. 2007. Relatório técnico sobre a situação atual da Piscicultura do estado do Amazonas. Manaus, AM.

Izel, A.C.U.; Crescêncio, R.; O’Sullivan, F.F.L. de A.; Chagas, E.C.; Boijink, C. de L.; Silva, J.I. 2013. Produção intensiva de tambaqui em tanques escavados com aeração. Manaus: Embrapa Amazônia Ocidental. 4 p.

Izel, A.C.U.; Melo, L.A.S. 2004. Criação de tambaqui (Colossoma macropomum) em tanques escavados no estado do Amazonas. Manaus: EMBRAPA. 20 p. (Documentos, 32).
Loose, C.E.; Sato, S.A. da S.; Aleixo, N.D.; Freitas, C.O.; Souza, D.F. da S. 2014. Custos na criação de tambaqui (Colossoma Macropomum Couvier,1818) nas propriedades participantes do Programa Peixe Forte em Cacoal (RO). In: Congresso Brasileiro De Custos, 21, Natal. Anais XXI CBC... Anais. Natal: CBC, nov. 2014.

Marinho-Pereira, T.; Barreiros, N.R.; Craveiro, J.M.C.; Cavero, B.A.S. 2009. O desempenho econômico na produção de tambaqui comparando dois sistemas de criação na Amazônia ocidental. Revista Ingepro, 1: 78 - 84.

Martin, N.B.; Scorvo Filho, J.D.; Sanches, E.G.; Novato, P.F.C; Ayrosa, L.M.S. 1995. Custo e retornos na piscicultura em São Paulo. Informações Econômicas. 25(1): 9-47.

Matsunaga, M. 1976. Metodologia de custo de produção utilizada pelo IEA. Agricultura em São Paulo, São Paulo, 23(1): $123-140$.

Núcleo Estadual de Apoio aos Arranjos Produtivos Locais de Rondônia [NEAPL/RO]. 2007. Núcleo Estadual de Arranjos Produtivos Locais de Rondônia. Arranjo Produtivo Local da Piscicultura de Pimenta Bueno - RO. Porto Velho $-\mathrm{RO}, 14 \mathrm{p}$.

Oliveira, A.M; Silva, M. de N.P da; Almeida-Val, V.M.F. de; Val, A.L. 2012. Caracterização da Atividade de Piscicultura nas Mesoregiões do Estado do Amazonas, Amazônia Brasileira. Revista Colombiana Cientifica de Animais, 4: 154162.

Padua, D.M.C.; Aguiar, M.S.; Boijink, C.L. 2008. A Piscicultura no Desenvolvimento do Estado de Goiás. In: Guerra, C.; Tejerina-Garro, F. L.; Pietrafesa, J. P. (Org.). Cerrado, Sociedade e Ambiente: desenvolvimento sustentável em Goiás. Goiânia: Editora da UCG. p. 275-303. 978-85-7103373-0.

Pantoja, J.L; Santos, S.M dos; Oliveira, A.T; Araújo, R.L; Santos-Júnior, J.A.L dos; Bernardino, G.; Alves, R.R. dos S.; Filho, A.F.; Gomes, A.L.; Aride, P.H.R. 2015. Pesquisa e transferência de tecnologia aliadas para o desenvolvimento da aquicultura no Estado do Amazonas. In: Tavares -Dias, M \& Mariano, W.S. (Org). Aquicultura no Brasil: novas perspectivas. São Carlos, editora Pedro \& João.

Pereira, S.L.A; Quadros. M; Porto, W.S; Santos, A.N.A. dos. 2013. Características da piscicultura no município de Mucajaí - Roraima. IV Congresso Brasileiro de Aquicultura de Espécies Nativas. 2013.

Riva, F.B; Carvalho, K.M.G de A.S; Oliveira, N.S; Filho, T.A de S.; Rosa, Q. da S. 2010. Disseminação de Conhecimento e Competitividade na Cadeia Produtiva da Piscicultura na Região de Ariquemes. $48^{\circ}$ Sociedade Brasileira de Economia, Administração e Sociologia Rural. Campo Grande, MS.

Rolim, P.R. 1995. A infra-estrutura básica para criação de peixes na Amazônia. In: Val, A.L.; Honczaryk, A. (Eds.) Criando peixes na Amazônia. INPA. Manaus/ Amazonas. p. 27-43.

Sales, E.B. 2009. Noções básicas de piscicultura. Porto Velho: EMATER/RO.

Serviço Brasileiro de Apoio às Micro e Pequenas Empresas de Roraima [SEBRAE-RR]. 2008. Diagnóstico da Cadeia Produtiva da Piscicultura de Boa Vista - Cantá - Amajarí Mucajaí - Alto Alegre. Boa Vista.

Secretaria de Produção Rural do Amazonas [SEPROR-AM]. 
2007. Relatório técnico sobre a situação atual da Piscicultura do estado do Amazonas. MANAUS - AM.

Sonoda, D.Y.; Shirota, R.; Campos, S.K.; Cyrino, J.E.P. 2012. Demand for fisheries products in Brazil. Scientia Agricola, 65(5): 313-319.

Sonoda, D.Y.; Shirota, R.; Scorvo Filho, J.D.; Cyrino, J.E.P. 2015. Desequilíbrio entre a oferta e a demanda brasileira por pescados em 2002/2003 e 2008/2009. Revista iPecege, 1(1): 9-21.

Sonoda, D.Y.; Cyrino, J.E.P; Shirota; R. 2016. Biomassa econômica de produção de tilápias em tanques-redes em propriedade rural no sudeste do Brasil. Revista iPecege, 2(4): 60-72.

Souza, D.F da S. 2014. Custos na criação de Tambaqui (Colossoma Macropomum) nas propriedades participantes do Programa Peixe Forte em Cacoal - RO/ Diogo Francisco da Silva Souza - Cacoal/RO: 29 f. UNIR. Disponível em: < https://anaiscbc.emnuvens.com.br/anais/article/ view/3751> Acesso em: 15 ago. 2018

Superintendência da Zona Franca de Manaus [SUFRAMA]. 2003. Relatório elaborado pela Câmara setorial da Agroindústria da Zona Franca de Manaus.

Val, A.L.; Rolim, P.R.; Rabelo, H. 2000. Situação atual da aqüicultura no Norte. Pags. 247-266. Em: Valenti, W.C.; Poli, C.R.; Pereira, J.A.; Borghetti, J.R. (Eds.). Aquicultura no Brasil. Bases para um desenvolvimento sustentável. CNPq/ Ministério da Ciência e Tecnologia, Brasília, Brasil.

Valenti, W.C. 2008. A aqüicultura Brasileira é sustentável? Palestra apresentada durante o IV Seminário Internacional de Aqüicultura, Maricultura e Pesca, Aquafair 2008, Florianópolis, 13-15 de maio de 2008. p. 1-1 Disponível em: <https://www.avesui.com> Acesso em: 10 ago. 2018. 